Texas A\&M University- San Antonio

Digital Commons@ Texas A\&M University-San Antonio

History Faculty Publications

College of Arts and Sciences

2000

\title{
Chronometers and Units in Early Archaeology and Paleontology
}

\author{
R. L. Lyman
}

Michael J. O'Brien

Texas A\&M University-San Antonio, Mike.Obrien@tamusa.edu

Follow this and additional works at: https://digitalcommons.tamusa.edu/hist_faculty

Cart of the Anthropology Commons

\section{Repository Citation}

Lyman, R. L. and O'Brien, Michael J., "Chronometers and Units in Early Archaeology and Paleontology" (2000). History Faculty Publications. 17.

https://digitalcommons.tamusa.edu/hist_faculty/17

This Article is brought to you for free and open access by the College of Arts and Sciences at Digital Commons @ Texas A\&M University- San Antonio. It has been accepted for inclusion in History Faculty Publications by an authorized administrator of Digital Commons @ Texas A\&M University- San Antonio. For more information, please contact deirdre.mcdonald@tamusa.edu. 


\title{
CHRONOMETERS AND UNITS IN EARLY ARCHAEOLOGY AND PALEONTOLOGY
}

\author{
R. Lee Lyman and Michael J. O’Brien
}

\begin{abstract}
Early in the nineteenth century, geologist Charles Lyell reasoned that successively older faunas would contain progressively more extinct species and younger faunas relatively more extant species. The present, with one-hundred percent extant species, was the chronological anchor. In archaeology a similar notion underpins the direct historical approach: Successively older cultures will contain progressively fewer of the cultural traits found in extant cultures and relatively more prehistoric traits. As in Lyell's scheme, the chronological anchor is the present. When A. L. Kroeber invented frequency seriation in the second decade of the twentieth century, he retained the present as a chronological anchor but reasoned that the oldest cultural manifestation would contain the highest percentage of a variant, or what came to be known as a "style," of an ancient trait, and successively younger cultural manifestations would have progressively lower percentages of that variant. The principle of overlapping permitted building sequences of fossils and artifacts, but differences in the units that allowed the chronometers to be operationalized reveal significant epistemological variation in how historical research is undertaken. This variation should be of considerable interest to paleobiologists and archaeologists alike, especially given recent archaeological interest in creating and explaining historical lineages of artifacts.
\end{abstract}

A principios del Siglo XIX, el geólogo Charles Lyell propuso que, sucesivamente, las faunas más antiguas tendrían progresivamente más especies extintas, y las faunas más jóvenes más especies existentes. El presente, con cien por ciento de las especies existentes, era el ancla cronológica. En arqueología una noción similar corrobora el enfoque histórico directo: sucesivamente las culturas más antiguas contendrían progresivamente menos características culturales que las encontradas en culturas existentes, y relativamente más características prehistóricas. Según el esquema de Lyell, el ancla cronológica es el presente. Cuando A. L. Kroeber, en la segunda década del Siglo XX, inventó la seriación de frecuencia, él conservó el presente como un ancla cronológica, pero postuló que la manifestación cultural más antigua contendría el porcentaje más alto de una variante, lo que fue conocido como un "estilo" de una característica antigua. Sucesivamente, las manifestaciones culturales más jóvenes tendrían progresivamente porcentajes más bajos de esa variante. El principio de yuxtaposición (superposición) permitió construir secuencias de fósiles y artefactos, pero diferencias en las unidades que permitieron operar a los cronómetros, revelan una variación epistemológica signification en cuanto a cómo conducir la investigación histórica. Esta variación sería de considerable interés para arqueólogos y paleobiólogos, especialmente dado el reciente interés arqueológico de crear y explicar los linajes históricos de artefactos.

"It is a good old rule to work from the known to the unknown." (E. B. Tylor 1881:10)

A rchaeologists and paleobiologists share a number of goals, and we suspect practitioners in both disciplines would agree that two of these are to determine and to explain the evolutionary history of humans and nonhuman organisms through study of the archaeological and paleontological records. Given that one must be able to determine analytically the ages of different portions of these prehistoric records, it is not surprising that there is overlap in the methods the two disciplines bring to bear on the problem of how to measure the passage of time. Both disciplines use Nicolaus Steno's principle of superposition, and both realize that superposition might allow one to determine the chronological order of the deposition of strata but not necessarily the relative ages of particles or sediments comprising the strata (e.g., Harper 1980; Rowe 1961). Further, both disciplines employ a form of chronostratigraphic correlation based on distinctive fossils and/or artifacts found within particular strata. This method is termed "biostratigraphy" in both geology - the discipline in which it was first developed

R. Lee Lyman = Department of Anthropology, University of Missouri, Columbia, MO 65211

Michael J. O'Brien - Department of Anthropology, University of Missouri, Columbia, MO 65211

American Antiquity, 65(4), 2000, pp. 691-707

Copyright (C) 2000 by the Society for American Archaeology 
(Rudwick 1996) — and paleontology (e.g., Eldredge and Gould 1977), and typological cross dating, or just cross dating, in archaeology (e.g., Patterson 1963).

Prior to the development of radiometric dating techniques in the 1950s, archaeologists and natural historians-geologists and paleontologists ${ }^{1}$ — used similar though not identical chronometers, or devices for measuring the passage of time. The similarities suggest that similar logic underlies each, but a critical difference resides in the kinds of units by which the chronometers are operationalized. Here we do not explore the historical nuances of interdisciplinary borrowing and cross-pollination-a topic that has been covered elsewhere in detail (see Chazan [1995], Grayson [1983], Sackett [1981], and Van Riper [1993] for Europe; see Lyman et al. [1997, 1998], Lyman and O'Brien [1999], and O'Brien and Lyman [1999a] for North America). Rather, our interest is in the chronometers themselves and the units they use to measure time. We first describe the geological chronometer and then turn to two chronometers developed by Americanist archaeologists. We explain the reasoning behind the chronometers and highlight epistemological and ontological similarities and differences between them.

One might ask why archaeologists should be concerned with early chronometers, especially given the current widespread use in archaeology (and paleontology) of radiometric dating, unless it is to view the devices merely as historical footnotes to the advent of, say, radiocarbon dating in the late 1940s (see Marlowe 1999; Taylor 1985, 1987). Given the important role that radiometric dating plays in modern archaeology, it is little wonder that today's students might view earlier efforts to establish chronological ordering as relatively imprecise and unworthy of in-depth study. We have several responses. First, even casual perusal of the large body of literature that grew out of the efforts of archaeologists working during the first half of the twentieth century reveals that they developed numerous clever methods to determine the ages of archaeological phenomena, often with considerable precision. These methods were not replaced by radiometric dating; rather, they supplemented, and continue to supplement, the new chronometer.

Second, we agree with Meltzer's (1989:12) comment that "the best way to understand why we do what we do is to unfold the beliefs that have structured, and continue to structure, our work." We also strongly agree with Bohannan and Glazer's (1988:xv) notation that ignorance of a discipline's past can result in "unnecessary originality," whereas knowledge of it can "give one a great many good ideas." For us, understanding the early development of chronometers in paleontology and archaeology, especially with respect to the kinds of units used in chronometry, has formed the backbone for the application of Darwinian evolutionary theory to understanding the archaeological record (e.g., Lyman and O'Brien 1998, 1999, 2000; O'Brien and Lyman 1999a, 2000a, 2000b, 2000c). Important issues that stem directly from our examination include the nature of the units employed to measure the passage of time, how time itself is viewed, and the implications of those issues for how Americanist archaeologists have explained culture change.

Evolutionary archaeology has as its basis (1) creating historical lineages of artifacts—what O'Hara (1988) calls the writing of evolutionary chronicles, and (2) explaining why lineages look the way they do-O'Hara's writing of narrative sentences. But unless we want to rewrite this modern interest in self-serving terms, we need to recognize that creating historical lineages of artifacts is not new to Americanist archaeology. Culture historians of the first half of this century were constantly engaged in such an endeavor, although the lineages they produced were more by-products of efforts aimed at bringing chronological control to the archaeological record than they were purposeful constructions. Regardless, evolutionary archaeology makes use of the same methods; hence anyone interested in applying them should know something not only about their history but also about how they differed epistemologically from other chronometric methods used in the natural sciences.

\section{A Chronometer for Geology and Paleontology}

The analytical principles and tools for interpreting earth history were developed at the end of the eighteenth and the beginning of the nineteenth centuries (Rudwick 1996), such that by 1830 geologists were attempting to build an understanding of earth history based on stratigraphic analysis. Their "attention was focused on the discovery of the correct order of succession of formations[, and] 'characteristic fossils' were being used with increasing confidence as the most reliable (though not the only) criterion for the correlation of formations in different regions" (Rudwick 1978:226). Geologists of the early nineteenth 
century were struggling to establish what are today's biostratigraphic methods, and in the process they were worrying about what was meant by similarities and differences among the fossil faunas represented in different geological formations (Hancock 1977; Mallory 1970; Rudwick 1978). The source of concern resided in the various forms of what can loosely be labeled notions of the history of life (Mayr 1982). These notions had to be sorted through and a particular one adopted if taxonomically similar yet geographically separate fossil faunas were to serve geological inquiry in any analytically useful way.

Late in the 1820s Charles Lyell sought to develop a method that could be used to arrange geological strata in proper chronological order. Lyell's chronometer, in effect a paleontological clock, had as its centerpiece the notion that the proportion of extant molluscan species in a fossil fauna could serve as an indication of that fauna's relative age. Significant portions of his discussion are found in chapters 4 and 5 of volume III of his Principles of Geology. In those chapters Lyell (1833) reasoned that the number of extant species relative to the number of extinct species would decrease as one moved back in time. In Lyell's (1833:59) words, there was an "increase of existing species, and gradual disappearance of the extinct, as we trace the series of formations from the older to the newer." This was a "radically original" idea for questions of geochronology, for as Rudwick (1990:xl) documents, Lyell was "not concerned merely to identify strata by a few specially characteristic fossils, as most of his contemporaries were doing. He [was] attempting instead to set up a roughly quantitative geological chronometer, which [would] indicate not merely the relative order of strata but also their absolute ages, although only approximately and not in years.' Lyell's faunal chronometer would, in other words, produce a clock much like Petrie's (1899) "sequence dates," but whereas Petrie suspected his clock kept time on an ordinal scale, Lyell could hope for an interval-scale chronometer because in his view the biota of the world changed "continuously and uniformly" (Rudwick 1990:xli).

Fully in line with anti-Lamarckian notions regarding the histories of species current at the time (Mayr 1982; Rudwick 1978, 1990), Lyell's faunal chronometer depended on the stability of species and their abrupt appearance in and disappearance from the fossil record. Lyell viewed species as real entities that had an initial appearance at one point in time, a period of occurrence, and a point in time when they became extinct. Thus for Lyell and many of his contemporaries, each species was a discrete entity, it had a distinct life span, it occupied one more or less distinct portion of the temporal continuum, and it did not (and could not) evolve into a new species over time. Species were not the arbitrary chunks of an evolutionarily continuous lineage as proposed by Darwin (1859) a quarter century later.

Lyell conceived of species as appearing and disappearing in "piecemeal" fashion (Rudwick 1978:233), although he provided no mechanism for their appearance other than to refer to them vaguely as the results of "intermediate causes" (K. M. Lyell 1881:467). Faunal turnover would be reflected in the fossil record by particular combinations of taxa occupying particular portions of the temporal continuum. In Lyell's view and in that of many of his contemporaries, each suddenly appearing new species would, given sufficient time, eventually become extinct. The identification of strata containing members of the same species "not only enables us to refer to the same era, distinct rocks widely separated from each other in the horizontal plane, but also others which may be considerably distant in the vertical series"(Lyell 1833:41). In Lyell's view, species could occur in more than one formation, and formations could be temporally ordered based on the particular combinations of species they contained. Recall that Lyell was not simply using one or a few index fossils as the basis of an ordering of formations; rather, he was using whole suites of species. This was a decidedly different approach than Lyell's contemporaries such as William Smith, Georges Cuvier, and Alexandre Brongniart (see Rudwick [1996] for references) were using in their stratigraphic-correlation work.

Despite the fact that several workers developed faunal chronometers similar to Lyell's, Rudwick (1978:241) suggests that they all failed to become a part of paleontology's analytical tool kit because of difficulties involved in identifying individual fossils as representing particular species. As Lyell (1833:49) noted, "the systematic arrangement of strata, so far as it rests on organic remains, must depend essentially on the accurate determination of species." For Lyell's fossil clock to work, fossil species A had always and everywhere to be identified consistently in the prehistoric record and to be readily distin- 


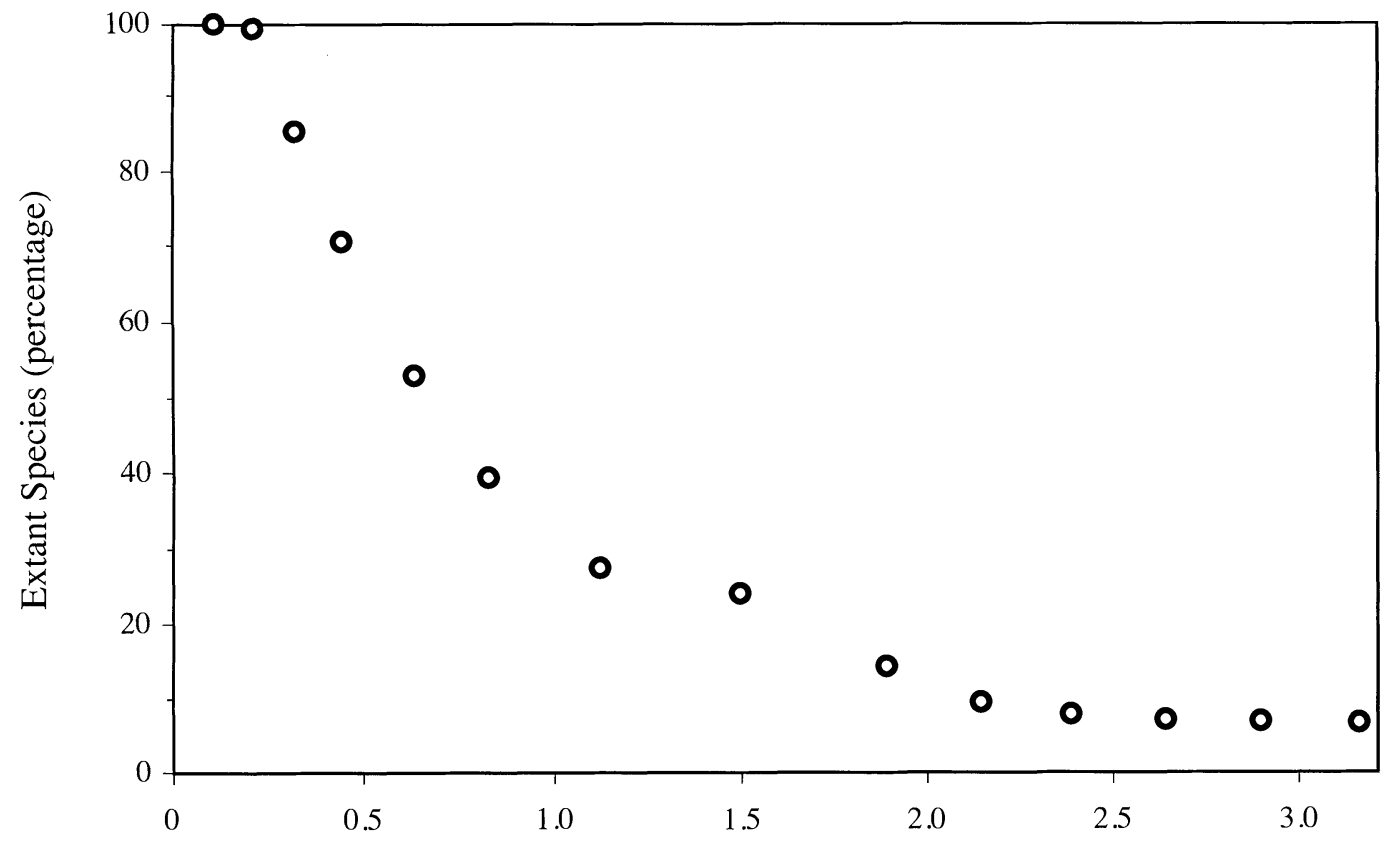

Age (millions of years)

Figure 1. An example of a Lyellian curve showing the percentage of extant mammalian species found in Europe during the Plio-Pleistocene (after Stanley 1979:114, Figures 5-8a).

guished from fossil species B, C, and D. Otherwise, the fluctuating relative frequencies of extant and extinct species would be a function of how fossils were identified taxonomically rather than a function of their actual occurrence in time. In addition, we suspect that once Darwin's (1859) views on biological evolution and on species as unstable entities that changed continuously were introduced, Lyell's chronometer was perceived as unworkable.

More than a hundred years later, species were again conceived of as being more or less stable, and Lyell's chronometer, like the phoenix, reappeared. Lyell's faunal chronometer today is graphed in what is termed "Lyellian curve" form (Stanley 1979:113). As exemplified in Figure 1, such graphs indicate the proportion of extant species or higher-level taxa in fossil faunas, or what is termed the "Lyellian percentage" (Stanley et al. 1980). Beginning with a modern fauna containing only extant species, fossil faunas are sorted such that the proportion of extant taxa progressively decreases from sample to sample; that the curve identified by the plotted points in fact measures time must be confirmed with independent data derived from such methods as stratigraphic observation or radiometric dating (Stanley et al. 1980). Given an absolute-dating technique, Lyellian curves show the rate of extinction of prehistoric taxa through time and the rate of origination of extant taxa (Stanley et al. 1980).

But there is a potentially fatal problem with constructing a Lyellian curve and thus with using it as a chronostratigraphic tool and interpreting the curve in terms of evolutionary processes. Lyell had hoped that his chronometer would eventually produce a universal chronostratigraphic device that could be applied worldwide, thereby allowing all strata to be correlated into one grand sequence of earth history. The problem, we now know, is that geographically separate populations of a taxon will not all be extirpated at the same time; spatially limited samples of fossils may thus produce inaccurate dates for the extinction of that taxon. In formal terms, homotaxial succession-similarity or identity in the spatial order of taxa from one locality to the next (Harper 1980)-does not necessarily equal chronological order. As Stanley et al. (1980:422) note, "to be strictly valid, the Lyellian approach to biostratigraphy requires that the entire world has been characterized by a particular tempo- 


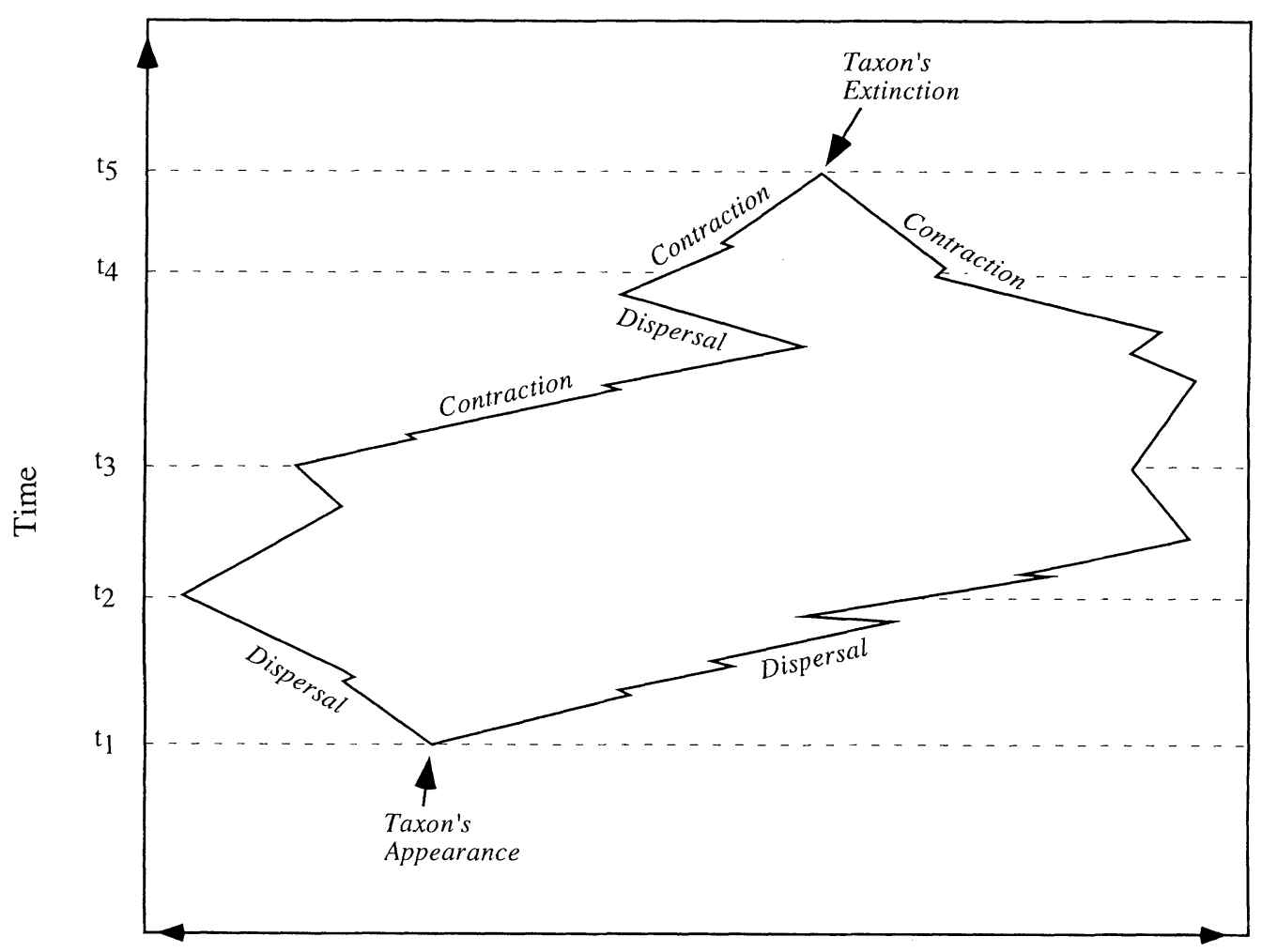

Geographic Space

Figure 2. A model of the spatiotemporal distribution of a biological taxon (after Pearson 1998:130, Figure 5.4).

ral pattern of extinction." This problem and the similar one of dating the first appearance of a taxon are well captured by the model of a taxon's spatiotemporal distribution shown in Figure 2. If the total real spatiotemporal range of a taxon is unknown, as is the case when only the left half of the distribution in Figure 2 is known, then the times of appearance and extinction of a taxon will influence the shape of the Lyellian curve based on such data. Archaeologists, as we will see in the next section, faced this same problem, and it plagued one of the chronometers they developed. Another was unaffected because it incorporated units that had a decidedly different distribution than that shown in Figure 2.

\section{Americanist Archaeology's Early Chronometers}

Archaeologists trained in the United States originally had little interest in time, largely because most of them generally believed that the time depth of human occupation of the Americas was shallow
(Meltzer 1983, 1985). Nonetheless, by the end of the nineteenth century, two chronometers were available. One, superposition and stratigraphic excavation (Lyman et al. 1997; Lyman and O'Brien 1999; O'Brien and Lyman 1999a), is not considered further here. The second chronometer, implemented through the direct historical approach, is of interest, as is a third chronometer, frequency seriation, which was developed during the second decade of the twentieth century. The latter two chronometers overlap considerably in technique and underpinning logic, and thus in how they are implemented, but they differ markedly in the units they employ and that allow their implementation. We discuss each in turn before comparing them with Lyell's faunal chronometer.

\section{Direct Historical Approach}

Willey and Sabloff (1993:126) indicate that the method known as the direct historical approach "is almost as old as archaeology." We agree. Cyrus Thomas (1894) used it to help resolve the mound- 
builder controversy in the late nineteenth century (Meltzer 1985; O’Brien and Lyman 1999b), and archaeologists working in the early twentieth century used it as well. For example, A. V. Kidder (1916) explicitly stated that one of the reasons he chose Pecos Pueblo, New Mexico, for excavation was that it had been occupied into the historical period, which allowed him to track time from the present back into the past. How does the approach work? The quote from E. B. Tylor that introduces this paper is a typical characterization; few additional details were provided in later years, although numerous culture historians used the method (e.g., Collins 1932; Stirling 1932; Strong 1935; Wedel 1938).

In the only detailed programmatic statement on the direct historical approach of which we are aware, Steward (1942:337) remarked that it "involves the elementary logic of working from the known to the unknown. First, sites of the historic period are located. ... Second, the cultural complexes of the [historical-period] sites are determined. Third, sequences are carried backward in time to protohistoric and prehistoric periods and cultures." The approach would allow one to "carry sequences backward beyond the point where the traits of the known, historic peoples faded out" (Steward 1942:338). Unfortunately, these few statements, along with the remainder of Steward's paper, did not specify what a "cultural complex" was, what a "sequence" was, or how the latter was to be "carried backward in time," whether beyond "historic peoples" or not. Apparently, given how the direct historical approach was implemented by those cited by Steward (1942), a cultural complex comprised a set of cultural traits more or less unique to a particular culture (e.g., Wedel 1938). Knowing that individual traits occurred in different complexes allowed one to trace those cultural traits backward through time across successively preceding cultural complexes. Steward (1942) did not make explicit that one was tracking "sequences" back through time using what was referred to as "the principle of overlapping"- -the same principle that guided Lyell's thinking.

In the first use of the term "overlapping" of which we are aware, Kidder (1924:45) noted that one can construct sequences "by the principle of overlapping," but he did not tell us what the term signified. Stirling (1929), Willey (1936), and Ford (1938a, 1938b) used the term, but none defined it. Spier provided an early clue as to what is meant by

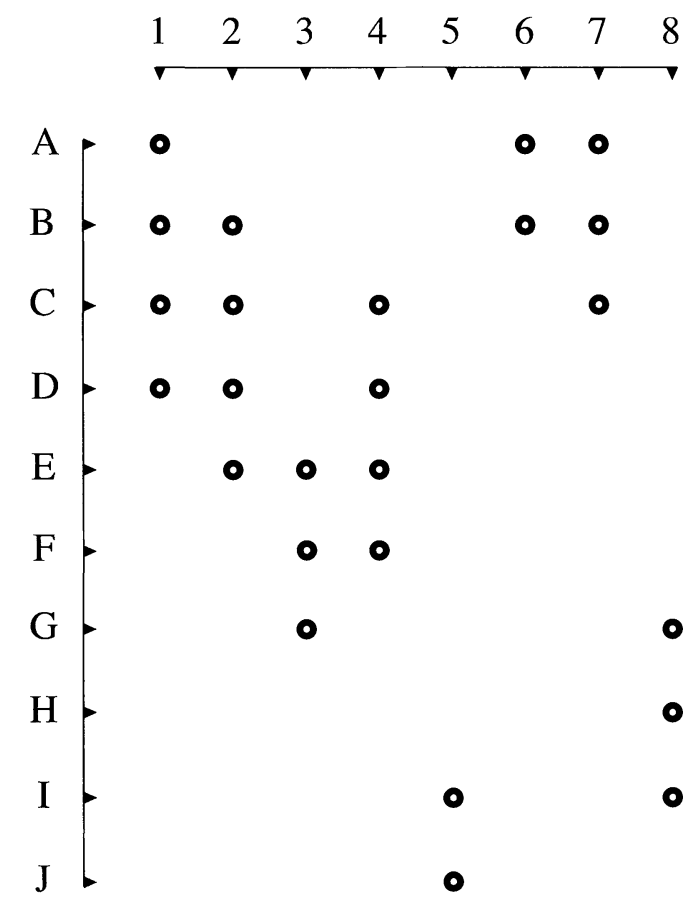

Figure 3. Diagram illustrating the principle of overlapping. Numbers 1-8 are units-for example, artifact types or biological taxa-used to order phenomena A-J-for example, artifact assemblages or geological strata. Overlap, or linkage, in ordering units hypothetically creates a sequence of phenomena being ordered by the fact that one or more units occur continuously across each pair of adjacent phenomena. As shown, time could be running in either direction through the sequence; additional information is needed to assess directionality. This "chronological anchor" could come from superposition, radiometric determination, or historical evidence.

the term when he discussed Kroeber's (1916a, 1916b) seminal frequency seriation. Kroeber noted that "the wares of the historic ruins overlapped with those of the [protohistoric period]; the latter, with the [ruins of the prehistoric period]" (Spier 1931:281). The principle of overlapping concerns the occurrence of a cultural trait in multiple cultural complexes or in artifact assemblages potentially of different age, and it is these shared, or overlapping, traits that serve as the basis for placing those complexes or assemblages adjacent to one another in an ordering thought to comprise a sequence (Figure 3). Overlapping thus is a form of "linkage" between archaeological phenomena (Ford 1938a:262; Strong 1935:68).

There are two significant aspects to the principle of overlapping, and both are found in Nelson's 
(1916:163) statement that when he excavated Pueblo San Cristobal, New Mexico, he was explicitly seeking data indicating that one type of pottery "gradually replac[ed]" another rather than seeking mere "time relations" of the types; he already knew the latter on the basis of the stratigraphic contexts of the types. Nelson (1916) excavated the way he did, and plotted ceramic type frequencies the way he did, because it was only in these ways that the gradual replacement of one or more types by one or more others-the overlapping of types across multiple assemblages - could be found. Each type would appear, persist for a while, and finally disappear, but the various types would do so in piecemeal fashion. The principle of overlapping is therefore critical to the direct historical approach precisely because, as Nelson (1916:163) noted, an overlapping trait—one shared by multiple assemblages or complexes"connects" them (Figure 3).

The two significant aspects of the principle of overlapping are that (a) it helps insure that time's passage is being measured and (b) it does so because it implies a particular kind of continuity. With respect to the first, the implicit assumption allowing application of the direct historical approach is that prehistoric materials more similar to historically documented materials - the more traits they shareare the more recent; prehistoric materials that are less similar to historically documented materials date to more remote times. This is much like the use of modern taxa to construct a Lyellian curve, and it is what allows sequences to be built. With respect to the second aspect, the connections of cultural complexes denoted by overlapping traits - traits shared by complexes adjacent to one another in an ordering - have a particular but implicit meaning that not only warrants the temporal inference but provides an explanation for that inference. The principle of overlapping assumes a direct phylogenetic connection-an evolutionary or geneticlike continuity founded on inheritance-between culture complexes that share traits (Lipo et al. 1997; O'Brien and Lyman 1999a, 2000a). Although implicit, this is why traits overlap from complex to complex and why the complexes are viewed as being linked. It was exactly such a connection that was explicitly sought by Nelson and referred to by Kidder, Spier, Ford, Willey, and others. The direct historical approach thus demands the study of homologous similarity, a point largely unrecognized (see Kroeber [1931, 1943] for rare explicit recognition) as the approach saw increased use during the first half of the twentieth century.

Rather than explore and develop the theoretical implications of the principle of overlapping-something being done now with increasing frequency (e.g., Lipo et al. 1997; Lyman and O'Brien 1998; Neiman 1995; O’Brien and Lyman 1999a, 2000a) culture historians discussed the value of the direct historical approach in strictly chronological terms. The approach was preferred by many early Americanist archaeologists because it provided "a fixed datum point to which sequences may be tied" (Steward 1942:337). That is, it provided a chronological anchor - in the historical period - to which archaeological materials of otherwise unknown relative age could be linked. Without a chronological anchor, sequences might be established, but they would have the unsavory characteristic of floating in time and perhaps have no indication of which way time was flowing through them. They would thus be of minimal utility in determining the developmental pathways of historically documented cultures. As Steward (1944:100) indicated, the direct historical approach "starts with the ready-made history contained in written documents. ... [T] [Te historic period is an excellent starting point for prehistoric sequences, especially where archaeological complexes now remain unfixed in time for want of stratigraphy or other reference points." Perhaps more important, "material from [historical-period and protohistoric] sites will show which [pottery-decoration] complex was the most recent and will determine which end of the chain of complexes constructed by overlapping is the latest. Without this tie-up it would be as logical for one end of the chronology to be recent as for the other" (Ford 1938a:263).

The direct historical approach was an obvious method for archaeologists to select, given their focus on writing the histories of various cultural lineages. We say it was obvious because it allowed them to trace those lineages from the present into the past. That the term "sequence" was used by Steward $(1942,1944)$ and others rather than the term "lineage" underscores the fact that archaeologists of the first half of the twentieth century were not thinking about cultural change in explicitly and well-developed evolutionary (phylogenetic) ways but primarily in terms of chronology. Overlapping was required only because it showed linkages between sets of material, not because it denoted heritable continuity. It is 
clear, however, that the latter is what warranted the inference of time's passage. Failure to explore the underpinning notion of heritable continuity between analytical units may have been exacerbated by the focus of anthropology in general on what were then known as "culture traits" or culture "elements." These were the units mentioned by archaeologists who used the direct historical approach (e.g., Steward 1929; Strong 1935), and they seem to have comprised what we elsewhere term "empirical units" (Lyman et al. 1997; O’Brien and Lyman 1998, 1999a, 2000a). We consider them further in a subsequent section.

\section{Frequency Seriation}

In 1915 Kroeber (1916a, 1916b) invented the archaeological chronometer that came to be known as frequency seriation (Lyman and O'Brien 1999; Lyman et al. 1997, 1998; O'Brien and Lyman 1998, 1999a). What is important here is the logic that underpinned Kroeber's invention. Kroeber noted, based on repeated observations in a geographically limited area, that corrugated pottery was regularly associated with dilapidated, nonhistorically documented ruins and that it was seldom found associated with less dilapidated, historically documented ruins. He then reasoned that this type of pottery would occur with greatest frequency among the oldest ruins and over time would decrease in frequency relative to other types until it no longer occurred. That is, successively younger ruins would have progressively lower relative abundances of that ancient type associated with them and would have progressively greater frequencies of types used by historic Zuni people. It was on this basis that Kroeber ordered 15 sites in what he suspected might be a chronological sequence, placing Zuni Pueblo as the sixteenth and most recent site in the series. Zuni was historically documented as having been occupied for much of the last several hundred years and had produced no specimens of the ancient pottery type (Kroeber 1916a, 1916b). Kroeber did not make explicit the fact that the principle of overlapping allowed him to order the sites and to infer that time's continuity was being measured by the ordering, or that the underpinning warrant for the use of the principle of overlapping comprised heritable continuity.

Simultaneous with Kroeber's work, Nelson (1916) plotted the absolute frequency of each of several artifact types against their vertical-recovery provenience in a column of sediment in order to mea- sure the passage of time. One year later, Spier (1917a, 1917b) and Kidder (Kidder and Kidder 1917) plotted the relative frequencies of each of several types of pottery from geographically limited areas against their superposed recovery positions to confirm what Kroeber and Nelson had found - relative frequencies of the pottery types fluctuated unimodally through time. This meant that types, if defined in particular ways on the basis of geographically limited samples, could be used in what came to be known as frequency seriation and percentage stratigraphy, and the latter two techniques could be used as chronometers. Within a few decades, however, percentage stratigraphy assumed center stage, and frequency seriation was relegated to a minor role in Americanist archaeology (Lyman and O'Brien 1999; O'Brien and Lyman 1999a). Important points in the present context concern Kroeber's reasoning and the units he and his contemporaries used.

First, just as with a paleontologist's Lyellian curve, the proof that an ordering of artifact assemblages produced by frequency seriation represents the passage of time must come from data independent of the seriation (Rowe 1961), a point Kroeber (1916b:20-21) recognized: "The final proof is in the spade.... [Otherwise,] in the present chaos of knowledge who can say which of these differences [in frequencies of sherd types] are due to age and which to locality and environment?' Second, in direct contrast to Lyell, Kroeber used a suspected ancient type as the basis for his ordering. Thus, what might be termed a "reverse Lyellian curve" results when Kroeber's most ancient type - the one that served as the major basis for his frequency seriation of sites - is plotted. This curve is shown in Figure 4. We call this a reverse Lyellian curve because the plot is based on the proportion of an ancient type rather than of a modern type, and thus the slope of the line defined by the plotted points is the reverse of that in a Lyellian curve (Figure 1). One of the two sites ("Kyakki W") that were exceptions to the principle of ordering - regular decrease in the relative abundance of the ancient type-was incorporated by Kroeber into his ordering on the basis of the relative abundance of another type suspected to be ancient and which met the ordering principle; the other site ("Kolliwa") was incorporated on the basis of the relative abundance of one apparently recent type that also met the ordering principle.

As with both Lyell's faunal chronometer and the 


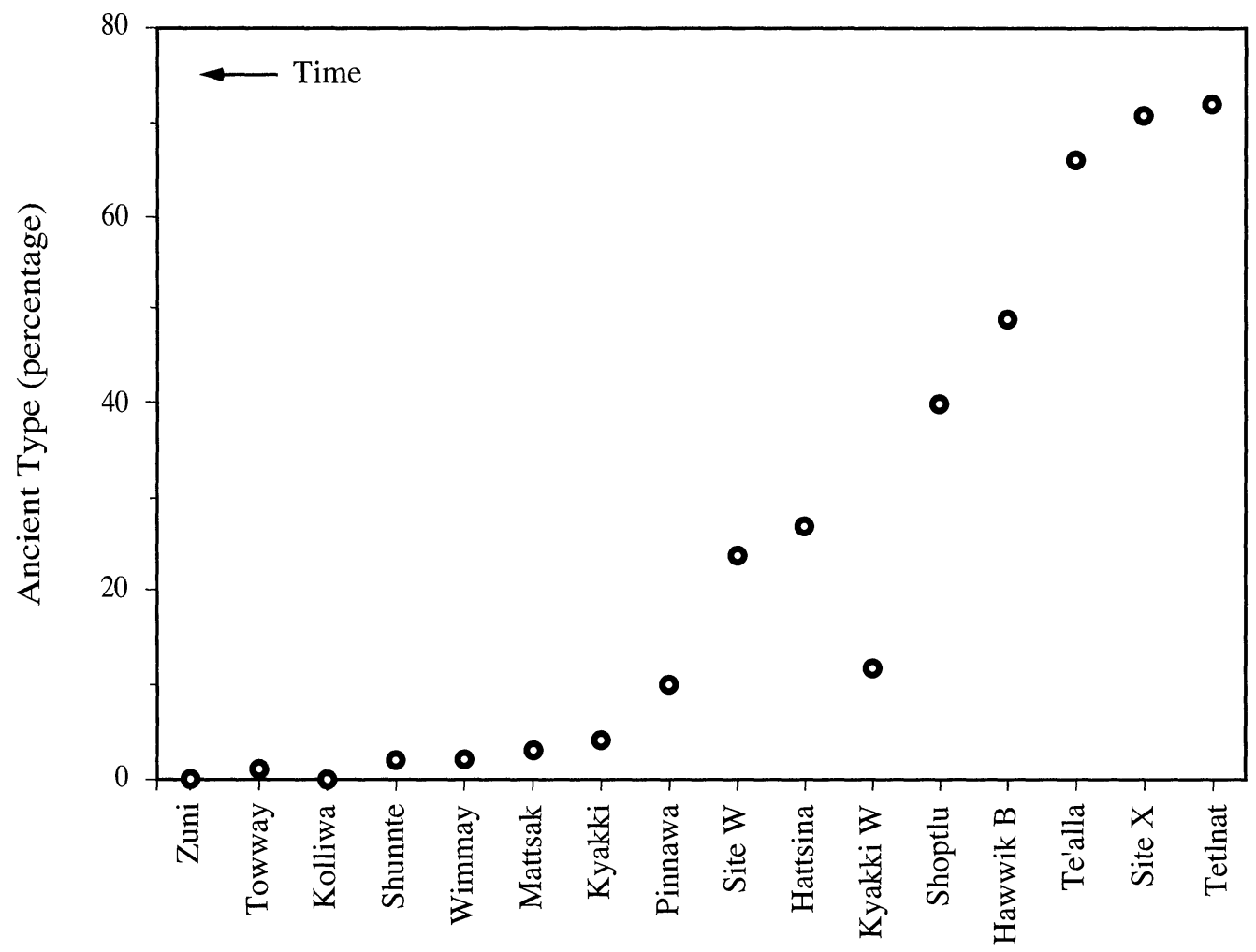

Figure 4. A reverse Lyellian curve for Kroeber's (1916a, 1916b) ceramic data from sites near Zuni Pueblo (site names abbreviated).

direct historical approach, overlapping was critical to Kroeber's production of a successful frequency seriation and Kidder's and Nelson's production of successful percentage-stratigraphy graphs-ones with types that, once collections were ordered, displayed unimodal-frequency distributions. But the most critical point here is that Kroeber, Nelson, Kidder, and Spier were not plotting frequencies of culture traits; they were instead plotting frequencies of variants of a trait (Lyman and O'Brien 1999). This is what allowed them to measure time. Overlapping was common to both frequency seriation and the direct historical approach, and it implied heritable continuity in both, although this implication was basically ignored. There was a shift in the scale of units used to operationalize the chronometer of frequency seriation from the more inclusive scale of culture trait used by the direct historical approacha scale consonant with Lyell's use of species-to that of trait variant. The units used by these archaeological chronometers, then, require further consideration.

\section{Units}

Kroeber's, Nelson's, Spier's, and Kidder's pottery types were viewed by them as analytical tools rather than as "real" entities, just as Ford viewed his types a few decades later (Lyman et al. 1997, 1998; O'Brien and Lyman 1998, 1999a, 2000a). One indication of this is that these units quickly became known as "styles" rather than as "cultural traits"; we are aware of only one reference to seriated units by the latter term (Wissler 1916), and it occurred just as the terminology was changing. The units plotted in Figure 4 are what are today known as styles or, more often, "historical types" (e.g., Krieger 1944; Rouse 1939). They are "ideational," specifically "theoretical," units - that is, they are simply units of measurement, just as is an inch or an ounce (Dunnell 1986; Lyman et al. 1997; O'Brien and Lyman 1999a). Such units are not real but rather are conceptual units, classes, that comprise particular combinations of properties, or attributes; at least some of those combinations will be displayed by real specimens. 


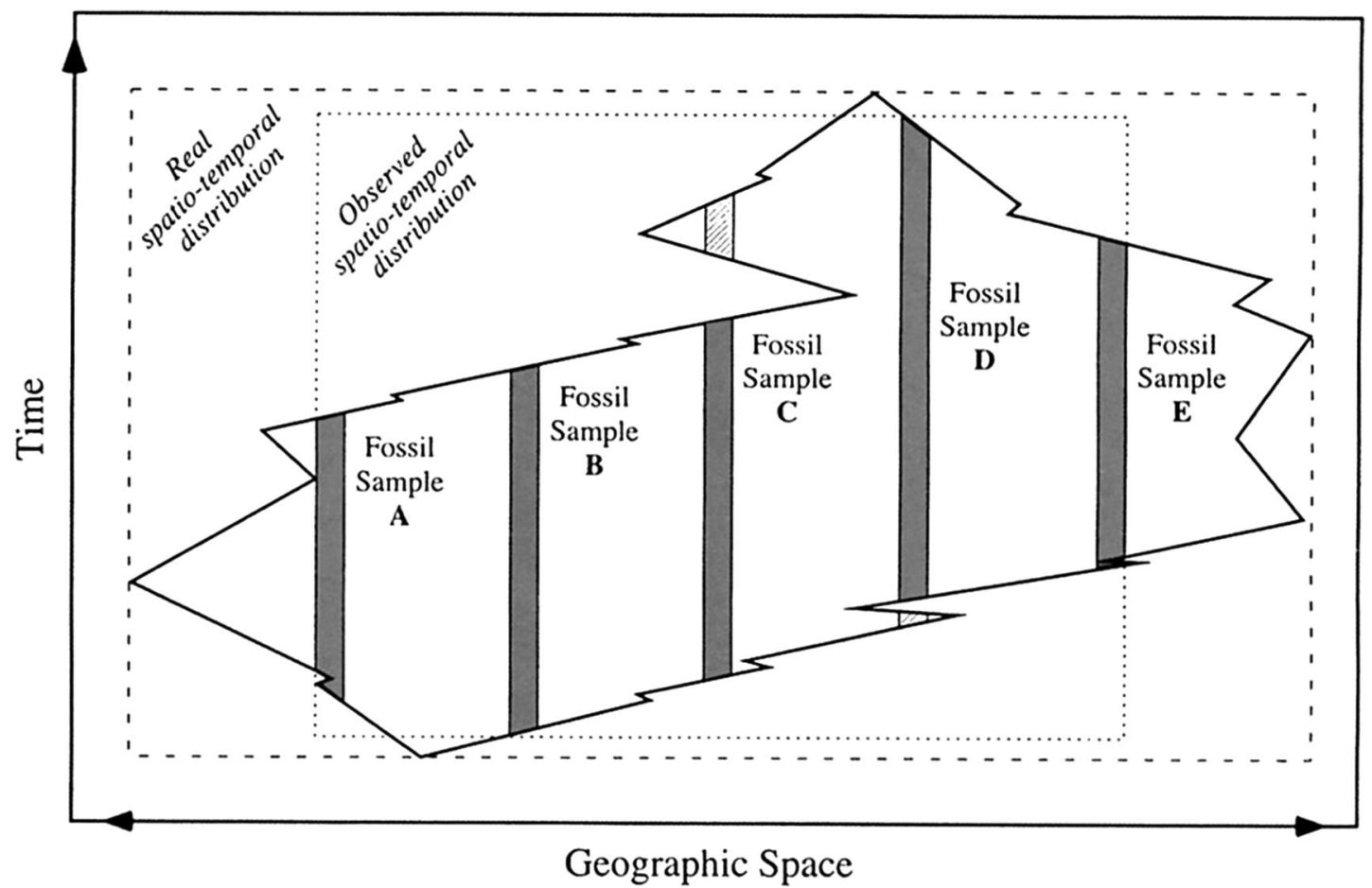

Figure 5. A model of what happens when the real spatiotemporal distribution of a biological taxon is converted into a unit that can be plotted in a Lyellian curve.

Recall that for Lyell species were fixed, immutable units. They were also real in the sense that one could go out into the world and observe them; Lyell's notion of uniformitarianism demanded that fossil species be real. Darwin showed that the notion that species were immutable was incorrect, although the empirical reality of species lives in the modern biological-species concept (e.g., Mayr 1982), which defines a species as a group of one or more populations comprising individuals that actually or potentially interbreed and that are reproductively isolated from other such groups (e.g., Mayr 1942, 1969). Many modern paleobiologists (e.g., Eldredge 1979; Eldredge and Gould 1972, 1977; Eldredge and Novacek 1985; Gould and Eldredge 1977, 1986, 1993; Vrba 1980) prefer the biological-species concept precisely because it has this biological meaning and therefore entails particular implications for biological evolution, not the least of which is punctuated equilibrium. Others (e.g., Fox 1986; Gingerich 1985; Rose and Bown 1986; Trueman 1979), realizing the problems involved in identifying interbreeding populations of organisms among inanimate fossils, employ the notion of chronospecies, which are more or less arbitrary chunks of the evolutionary, that is, morphological, continuum.

When drawing a Lyellian curve founded on units such as biological species, one must keep in mind the model of a species's spatiotemporal distribution shown in Figure 2. In drawing a Lyellian curve, a species's distribution is effectively converted to a rectangle. This conversion brings with it two problems that are graphically depicted in Figure 5. First, the real distribution may be much more complex than the relatively simple one displayed in Figure 5; the more complex the real distribution, the greater the number of samples necessary to approximate that distribution accurately. Even the relatively simple real distribution shown in Figure 5 will be poorly approximated if only samples A, C, and E in the figure are available. Second, the more complex the real distribution, or the less adequate the available samples, the greater the discrepancy between the perceived and real distributions.

Kroeber, Nelson, Kidder, and Spier escaped these problems in archaeology by constructing ideational units of a particular kind--analytical units that allowed them to measure time while simultaneously 


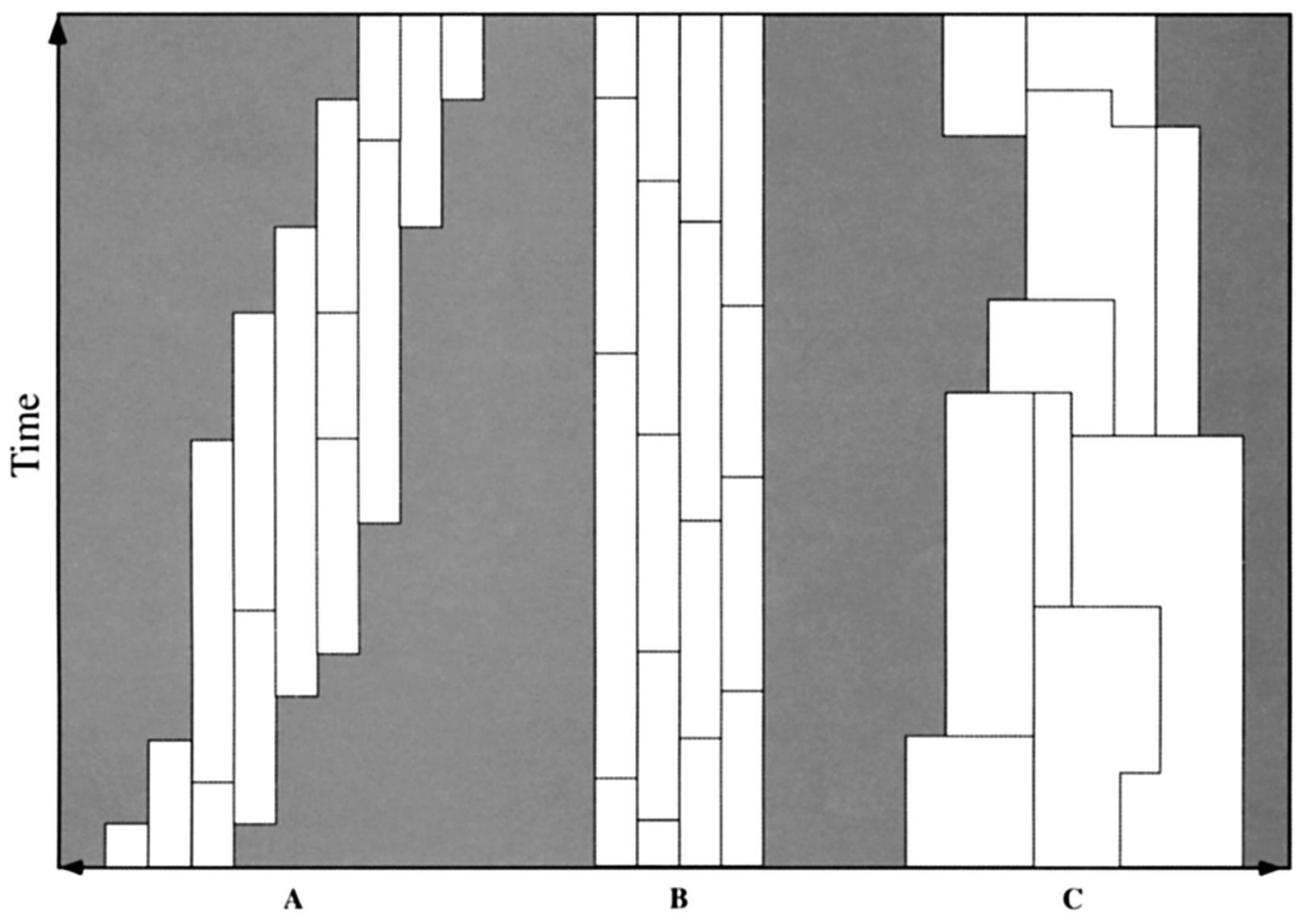

Geographic Space

Figure 6. Models of the spatiotemporal distribution of units (polygons) used to measure time (morphology varies continuously along both axes).

controlling the spatial dimension. Given the view that artifact form varies more or less continuously both over time and across space, they built analytical units to have limited spatiotemporal distributions. To illustrate this, consider Figure 6. In this figure artifact form varies continuously along both axes, but there is no absolute scale on either axis. Each polygon represents an ideational unit used during analysis to measure variation; shaded areas represent formal variation not measured by those units. Each column of polygons (A-C) denotes a set of analytical units comprising a typology. In column $A$ analytical units overlap through time but include spatial variation as well; thus change over time as well as variation over space is included. In column B analytical units overlap through time but do not include much spatial variation in form; thus only time is measured. In column $C$ variation in time and space varies from unit to unit, and although units measure time and thus change, they also measure a great deal of spatial variation in form.
The types constructed by Kroeber, Nelson, Spier, and Kidder approximated the rectangles shown in Figure 6, column B. That is, they monitored the passage of time rather than difference in geographic location. This kind of analytical unit comprises what came to be known as a historical type, or style, and it had to be built by trial and error (Rouse 1939)—a point rarely acknowledged explicitly. Given such a mode of construction, the utility of a type for measuring the passage of time had to be tested-a significant point made explicit by Krieger (1944) when he indicated that archaeologically useful types must pass the historical-significance test. The test implications were that a useful historical type had to have a distribution similar to one of those shown in Figure 6 , column B. Types that had distributions such as those in Figure 6, columns $A$ and $C$ could be used, but they were less satisfactory in that they measured variation in space as well as variation in time. If the constructed types did not pass the historical-significance test, they were discarded and new types were 
erected. This trial-and-error, classify-test-reclassify process continues to this day (e.g., O'Connell and Inoway 1994; Thomas 1981) as archaeologists attempt to construct analytical units that allow them to measure the passage of time reliably and validly.

Species and artifact types might display distributions such as those signified by the rectangles in Figure 6, column B, but this is unknown when the units are first constructed. Whether or not the constructed units have such distributions is what is determined by the historical-significance test. Species units often have spatiotemporal distributions such as that shown in Figure 2 and thus are potentially less reliable and valid measures of time. The complete spatial distribution of a species must be known in order to account for the taxon's varied spatial distribution over time. In short, the worldwide distribution of the taxon must be known so that the time of that taxon's appearance and extinction can be determined accurately. This is not the case with the analytical units used by early archaeologists; they built their units to have limited spatiotemporal distributions such that they were useful for measuring time. The closer those units approximated the units depicted in Figure 6, column B, the more closely and precisely they measured the passage of time.

In contrast to the "styles" used in frequency seriation, units used by those who applied the direct historical approach were said to be "culture traits" (e.g., Wedel 1938). The only definition for this kind of unit of which we are aware is Wissler's (1923:50): " a unit of observation ... a unit of tribal culture." These units were much like Lyell's species in that they were considered to be visible, real entities. Although they were generally inclusive units, culture traits could vary tremendously in scale-from a religious ceremony such as the Ghost Dance to a design motif on a ceramic vessel. They might change over time as a result of various processes (e.g., Barnett [1940, 1942] and references therein), but they were empirical units nonetheless. Culture traits often had distributions such as that modeled in Figures 2, 5, and 6 (columns $A$ and $C$ ), and this resulted in no end of debate over what their historical significance might comprise (e.g., Steward 1929). Further, they did not consistently measure the passage of time. But once the shift was made to historically sensitive variants of those traits - to what came to be known as styles, or historical types-time could successfully and more consistently be measured (Lyman and O'Brien 1999).

\section{Discussion}

As chronometers, Lyellian curves, the direct historical approach, and frequency seriation share a number of properties. Each begins with a chronological anchor in the present, and each traces time backward by tracking changes in the frequencies of units based on the principle of overlapping. On the one hand, in archaeology this principle serves as a warrant not only for the purely temporal sequence of archaeological manifestations but also for the inference that the sequence comprises a cultural lineage — a line of heritable continuity — or what came to be known as a tradition. A (cultural) tradition is usually defined as "a (primarily) temporal continuity represented by persistent configurations in single technologies or other systems of related forms" (Willey and Phillips 1958:37) or as "a socially transmitted cultural form which persists in time" (Thompson 1956:39). The latter in particular underscores that a tradition is a lineage, or line of heritable continuity (Lipo et al. 1997; Lyman and O'Brien 1998, 1999; O'Brien and Lyman 1999a, 2000a, 2000b, 2000c), and it emphasizes the warrant required by the direct historical approach and frequency seriation as chronometers.

Lyell's chronometer, on the other hand, required no such warrant. Lyell believed in the absolute stability of species and did not accept either the Lamarckian notion of transmutation or any of the other versions of biological evolution then being discussed. It was the piecemeal appearance and disappearance of taxa over time and their fixed, nonevolving nature that allowed Lyell to construct his chronometer. We suspect the fact that taxa evolve dissuaded geologists and paleobiologists from using Lyellian curves for over a century. Only in the last two or three decades have these curves been resurrected as useful analytical devices, and that resurrection came at the hands of those who view species as evolutionarily stable entities (e.g., Stanley 1979; Stanley et al. 1980) as opposed to constantly changing configurations.

Other parallels in dating techniques used by paleontologists and archaeologists are pertinent here. Archaeologists today use frequency seriation as a relative dating technique when chronometric techniques cannot be used (e.g., Allen 1996; Johnson and Nelson 1990; Love 1993; Rafferty 1994), and they use theoretical units to build their seriations. Paleontol- 
ogists continue to use species as the unit of choice when they do biostratigraphic analyses and have expanded their tool kit to include what archaeologists term "interdigitation" (Lyman et al. 1998; O'Brien and Lyman 1998) and they term "slotting" (e.g., Gordon and Reyment 1979). Paleobiologists rarely have used frequency seriation (but see Brower and Burroughs [1982] and McKee et al. [1995]), probably because they employ species as the units seriated and are well aware of the problems in so doing (Figures 2 and 5). Some paleobiologists (e.g., Gould et al. 1987) derogate frequency seriation, but it is clear they do not understand the ontological differences between units imposed through the use of the biological-species concept and the theoretical units upon which frequency seriation depends (O'Brien and Lyman 2000a). Here is where each discipline can assist the other.

The difference between (a) the units paleobiologists use to construct Lyellian curves and archaeologists use in the direct historical approach and (b) the theoretical units used in frequency seriation is important. The model in Figures 2 and 5 comprises the spatiotemporal distribution of an empirical unit termed a "biological species" (Pearson 1998), and it applies equally well as a characterization of the distribution of many culture traits. Such a unit has significant analytical constraints, the most important one in terms of measuring time being that its total spatiotemporal distribution must be known for a chronometer to be reliable and valid. Conversely, the kinds of units required by frequency seriation must be theoretical units that have spatiotemporal distributions like those in Figure 6, column B-that is, spatiotemporally limited distributions. Recognition of this point could result in paleobiologists using such units in frequency seriations and interdigitation, or slotting, to create faunal chronologies of much greater resolution than are currently available. Similarly, recognition could result in archaeologists becoming more interested in exploring the implications of overlapping units as they pertain to heritability, transmission mechanisms, and rates of transmission.

Previous discussions of the direct historical approach have been vague with respect to the principle of overlapping and its analytical and interpretive significance. Steward (1942) did not mention the principle at all in his discussion; those who used the term "overlapping" typically did not even indicate what the term meant analytically - the occurrence of a culture trait in more than one cultural complexlet alone why its occurrence should allow the construction of a cultural sequence. Our impression is that everyone knew what it meant for analysis, and we suspect as well that everyone also knew at least implicitly why cultural chronologies built using the direct historical approach comprised cultural lineages. The approach emerged as a commonly used method in Americanist archaeology between about 1910 and 1940, precisely when stratigraphic excavation, percentage stratigraphy, frequency seriation, and the Midwestern Taxonomic Method were gaining popularity in the discipline (Lyman et al. 1997), prompting Steward's (1942) post hoc programmatic statement (see also Steward 1944). The underpinning ontology of all these methods - evolutionary descent with modification of cultural complexes-escaped comment because the discipline-wide understanding of cultural evolution was couched within commonsensical notions of change over time. Even the mechanism insuring hereditary continuity—cultural transmission - was seldom remarked because it was generally understood as a given (Lyman 2000). Thus we are not surprised that the direct historical approach has not previously been subjected to critical evaluation and discussion.

\section{Conclusion}

If one goal of a discipline is to write the history of its subject phenomena, then a means of measuring time must be developed. If another goal is to explain in historical terms why modern subject phenomena such as organisms and cultures have the appearance they do, then sequences alone are insufficient. Those sequences must somehow be linked to the modern phenomena through the creation of lineages. Lyell's paleontological clock, the direct historical approach, and frequency seriation as implemented by Kroeber accomplished both goals by using the principle of overlapping. Yet the units used-species, culture traits, and historical types, respectively-were ontologically distinct. Lyell saw no evolutionary connections between species; for him they were nonchanging, essentialist units. Anthropologists and archaeologists, however, appear to have conceived of just such connections between culture traits, but because such units often had spatiotemporal distributions like those of biological species, they were not always useful for measuring time. Kroeber, Nelson, 
Kidder, and Spier implicitly viewed evolutionary connections between artifacts, but they also constructed units-types, or styles - that had spatiotemporally restricted distributions. These allowed them to measure the passage of time.

Lyell's chronometer could not be used when species were thought of as evolutionarily unstable entities, but when they were again viewed as stable units, his chronometer was resurrected. Archaeologists continued to use the direct historical approach after stratigraphic excavation became commonplace and frequency seriation was invented. We suspect part of its continued use resided in an analytical shift from units comprising culture traits to ones comprising artifact styles. Frequency seriation (and percentage stratigraphy) was successful because its analytical units were theoretical and built specifically to measure time. Failure to explore the theoretical implications of overlapping - the principle common to all three chronometers-resulted from a commonsense understanding of culture change, a focus on measuring time's passage alone, and a failure to recognize variation in the epistemology and ontology that underpin historical research.

There has been, however, a shift in emphasis from using theoretical units to measure time through the construction of sequences to using them to create historical artifact lineages. That is, there has been a shift toward exploring the theoretical implications of overlapping (e.g., Lipo et al. 1997; Lyman and O'Brien 1998, 1999; O’Brien and Lyman 1999a, 2000a, $2000 \mathrm{~b}, 2000 \mathrm{c}$ ). The units used in such analysis are classes, and they by-pass the problems created by using units that have widespread spatiotemporal distributions. They are, in effect, similar to the narrow units used by Nelson, Kidder, Kroeber, Spier, Ford, Willey, and others, but they are constructed to measure such things as social interaction and transmission-the processes that created the chronological overlap in the first place. To create historically accurate lineages requires that the units reflect phylogenetic relatedness. This in turn requires that percentage stratigraphy or frequency seriation be used to insure that a line of heritable continuity rather than a simple sequence is being examined. This shift in interest isn't really a new one in archaeology; culture historians of the early twentieth century had similar interests, but they did not ground that interest in formal theory. What they did do, however, was to create several excellent chronometers, thereby giving us the methodological grounds for creating and examining lineages. This is a heretofore underappreciated contribution but one that is fundamental to writing historical narratives of the archaeological record.

Acknowledgments. We thank D. Glover for producing the figures and E. J. O'Brien, J. Darwent, S. Wolverton, L. Goldstein, G. R. Willey, and two anonymous reviewers for their helpful comments on earlier drafts.

\section{References Cited}

Allen, M. S.

1996 Style and Function in East Polynesian Fish-Hooks. Antiquity 70:97-116.

Barnett, H. G.

1940 Culture Processes. American Anthropologist 42:21-48.

1942 Invention and Culture Change. American Anthropologist 44:14-30.

Bohannan, P., and M. Glazer (editors)

1988 High Points in Anthropology. 2nd ed. McGraw-Hill, New York.

Brower, J. C., and W. A. Burroughs

1982 A Simple Method for Quantitative Biostratigraphy. In Quantitative Stratigraphic Correlation, edited by J. M. Cubitt and R. A. Reyment, pp. 61-83. Wiley, Chichester, England.

Chazan, $\mathrm{M}$.

1995 Conceptions of Time and the Development of Paleolithic Chronology. American Anthropologist 97:457-467.

Collins, H. B.

1932 Archaeology of Mississippi. In Conference on Southern Pre-History, pp. 37-42. National Research Council, Washington, DC.

Darwin, C.

1859 On the Origin of Species. Murray, London.

Dunnell, R. C.

1986 Methodological Issues in Americanist Artifact Classification. Advances in Archaeological Method and Theory 9:149-207.

Eldredge, N.

1979 Alternative Approaches to Evolutionary Theory. In Models and Methodologies in Evolutionary Theory, edited by $\mathrm{J}$. H. Schwartz and H. B. Rollins, pp. 7-19. Carnegie Museum of Natural History, Bulletin 13. Pittsburgh.

Eldredge, N., and S. J. Gould

1972 Punctuated Equilibria: An Alternative to Phyletic Gradualism. In Models in Paleobiology, edited by T. J. M. Schopf, pp. 82-115. Freeman, Cooper, San Francisco.

1977 Evolutionary Models and Biostratigraphic Strategies. In Concepts and Methods of Biostratigraphy, edited by E. G. Kauffman and J. E. Hazel, pp. 25-40. Dowden, Hutchinson and Ross, Stroudsburg, PA.

Eldredge, N., and M. J. Novacek

1985 Systematics and Paleobiology. Paleobiology 11:65-74. Ford, J. A.

1938a A Chronological Method Applicable to the Southeast. American Antiquity 3:260-264.

1938b An Examination of Some Theories and Methods of Ceramic Analysis. Unpublished M.A. thesis, Department of Anthropology, University of Michigan, Ann Arbor.

Fox, R. C.

1986 Species in Paleontology. Geoscience Canada 13:73-84.

Gingerich, P. D. 
1985 Species in the Fossil Record: Concepts, Trends, and Transitions. Paleobiology 11:27-41.

Gordon, A. D., and R. A. Reyment

1979 Slotting of Borehole Sequences. Journal of the International Association of Mathematical Geology 11:309-327.

Gould, S. J., and N. Eldredge

1977 Punctuated Equilibria: The Tempo and Mode of Evolution Reconsidered. Paleobiology 3:115-151.

1986 Punctuated Equilibrium at the Third Stage. Systematic Zoology 35:143-148.

1993 Punctuated Equilibrium Comes of Age. Nature 366:223-227.

Gould, S. J., N. L. Gilinsky, and R. Z. German

1987 Asymmetry of Lineages and the Direction of Evolutionary Time. Science 236:1437-1441.

Grayson, D. K.

1983 The Establishment of Human Antiquity. Academic Press, New York.

Hancock, J. M.

1977 The Historic Development of Concepts of Biostratigraphic Correlation. In Concepts and Methods of Biostratigraphy, edited by E. G. Kauffman and J. E. Hazel, pp. 3-22. Dowden, Hutchinson and Ross, Stroudsburg, PA.

Harper, C. W., Jr.

1980 Relative Age Inference in Paleontology. Lethaia 13:239-248.

Johnson, K. W., and B. C. Nelson

1990 The Utina: Seriations and Chronology. The Florida Anthropologist 43:48-62.

Kidder, A. V.

1916 Archeological Explorations at Pecos, New Mexico. National Academy of Sciences, Proceedings 2:119-123.

1924 An Introduction to the Study of Southwestern Archaeology, with a Preliminary Account of the Excavations at Pecos. Papers of the Southwestern Expedition, Phillips Academy No. 1. Andover, MA.

Kidder, M. A., and A. V. Kidder

1917 Notes on the Pottery of Pecos. American Anthropologist 19:325-360.

Krieger, A. D.

1944 The Typological Concept. American Antiquity 9:271-288

Kroeber, A. L.

1916a Zuñi Culture Sequences. National Academy of Sciences, Proceedings 2:42-45.

1916b Zuñi Potsherds. American Museum of Natural History, Anthropological Papers 18:1-37.

1931 Historical Reconstruction of Culture Growths and Organic Evolution. American Anthropologist 33:149-156.

1943 Structure, Function and Pattern in Biology and Anthropology. Scientific Monthly 56:105-113.

Lipo, C. P., M. E. Madsen, R. C. Dunnell, and T. Hunt

1997 Population Structure, Cultural Transmission, and Frequency Seriation. Journal of Anthropological Archaeology $16: 301-334$

Love, M. W.

1993 Ceramic Chronology and Chronometric Dating: Stratigraphy and Seriation at La Blanca Guatemala. Ancient Mesoamerica 4:17-29.

Lyell, C.

1833 Principles of Geology, vol. 3. Murray, London.

Lyell, K. M.

1881 The Life, Letters and Journals of Sir Charles Lyell, vol. 1. Murray, London.

Lyman, R. L.

2000 Culture Historical and Biological Approaches to Identifying Homologous Traits. In Function and Style Twenty
Years Later, edited by T. Hurt and G. Rakita. Greenwood Press, Westport, CT, in press.

Lyman, R. L., and M. J. O'Brien

1998 The Goals of Evolutionary Archaeology: History and Explanation. Current Anthropology 39:615-652.

1999 Americanist Stratigraphic Excavation and the Measurement of Culture Change. Journal of Archaeological Method and Theory 6:55-108.

2000 Measuring and Explaining Change in Artifact Variation with Clade-Diversity Diagrams. Journal of Anthropological Archaeology 19:39-74.

Lyman, R. L., M. J. O’Brien, and R. C. Dunnell

1997 The Rise and Fall of Culture History. Plenum, New York.

Lyman, R. L., S. Wolverton, and M. J. O'Brien

1998 Seriation, Superposition, and Interdigitation: A History of Americanist Graphic Depictions of Culture Change. American Antiquity 63:239-261.

Mallory, V. S.

1970 Biostratigraphy-A Major Basis for Paleontologic Correlation. In Proceedings of the North American Paleontological Convention, edited by E. L. Yochelson, pp. 553-566. Allen Press, Lawrence, KS.

Marlowe, G.

1999 Year One: Radiocarbon Dating and American Archaeology, 1947-1948. American Antiquity 64:9-32.

Mayr, E.

1942 Systematics and the Origin of Species. Columbia University Press, New York.

1969 Principles of Systematic Zoology. McGraw-Hill, New York.

1982 The Growth of Biological Thought: Diversity, Evolution, and Inheritance. Harvard University Press, Cambridge, MA.

McKee, J. K., J. F. Thackeray, and L. R. Berger

1995 Faunal Assemblage Seriation of Southern African Pliocene and Pleistocene Fossil Deposits. American Journal of Physical Anthropology 96:235-250.

Meltzer, D. J.

1983 The Antiquity of Man and the Development of American Archaeology. Advances in Archaeological Method and Theory 6:1-51.

1985 North American Archaeology and Archaeologists 1879-1934. American Antiquity 50:249-260.

1989 A Question of Relevance. In Tracing Archaeology's Past: The Historiography of Archaeology, edited by A. L. Christenson, pp. 5-19. Southern Illinois University Press, Carbondale.

Neiman, F. D.

1995 Stylistic Variation in Evolutionary Perspective: Implications for Middle Woodland Ceramic Diversity. American Antiquity 60:7-36.

Nelson, N. C.

1916 Chronology of the Tano Ruins, New Mexico. American Anthropologist 18:159-180.

Nowlan, G. S.

1986 Paleontology: Ancient and Modern. Geoscience Canada 13:67-72.

O'Brien, M. J., and R. L. Lyman

1998 James A. Ford and the Growth of Americanist Archaeology. University of Missouri Press, Columbia.

1999a Seriation, Stratigraphy, and Index Fossils: The Backbone of Archaeological Dating. Kluwer Academic/Plenum, New York

1999b The Bureau of American Ethnology and Its Legacy to Southeastern Archaeology. Journal of the Southwest 41:407-440.

2000a Applying Evolutionary Archaeology: A Systematic 
Approach. Kluwer Academic/Plenum, New York.

2000b Evolutionary Archaeology: Reconstructing and Explaining Historical Lineages. In Social Theory in Archaeology, edited by M. B. Schiffer, pp. 126-142. University of Utah Press, Salt Lake City.

2000c Darwinian Evolutionism Is Applicable to Historical Archaeology. International Journal of Historical Archaeology 4:71-112.

O'Connell, J. F., and C. M. Inoway

1994 Surprise Valley Projectile Points and Their Chronological Implications. Journal of California and Great Basin Anthropology 16:162-198.

O'Hara, R. J.

1988 Homage to Clio, or, toward an Historical Philosophy for Evolutionary Biology. Systematic Zoology 37:142-155.

Patterson, T. C.

1963 Contemporaneity and Cross-Dating in Archaeological Interpretation. American Antiquity 28:389-392.

Pearson, P. N.

1998 Evolutionary Concepts in Biostratigraphy. In Unlocking the Stratigraphical Record: Advances in Modern Stratigraphy, edited by P. Doyle and M. R. Bennett, pp. 123-144. Wiley, Chichester, England.

Petrie, W. M. F.

1899 Sequences in Prehistoric Remains. Journal of the Royal Anthropological Institute of Great Britain and Ireland 29:295-301.

Rafferty, J.

1994 Gradual or Step-Wise Change: The Development of Sedentary Settlement Patterns in Northeast Mississippi. American Antiquity 59:405-425.

Rose, K. D., and T. M. Bown

1986 Gradual Evolution and Species Discrimination in the Fossil Record. In Vertebrates, Phylogeny, and Philosophy, edited by K. M. Flanagan and J. A. Lillegraven, pp. 119-130. University of Wyoming, Contributions to Geology, Special Paper No. 3. Laramie.

Rouse, I. B.

1939 Prehistory in Haiti: A Study in Method. Yale University Publications in Anthropology No. 21. New Haven, CT.

Rowe, J. H.

1961 Stratigraphy and Seriation. American Antiquity 26:324-330.

Rudwick, M. J. S

1978 Charles Lyell's Dream of a Statistical Paleontology. Paleontology 21:225-244.

1990 Introduction. In (a reprint of the first edition of) Principles of Geology, by C. Lyell, pp. vii-lv. University of Chicago Press, Chicago.

1996 Cuvier and Brongniart, William Smith, and the Reconstruction of Geohistory. Earth Sciences History 15:25-36.

Sackett, J. R.

1981 From de Mortillet to Bordes: A Century of French Palaeolithic Research. In Towards a History of Archaeology, edited Spier, L. by G. Daniel, pp. 85-99. Thames and Hudson, London.

1917a An Outline for a Chronology of Zuñi Ruins. American Museum of Natural History, Anthropological Papers 18:207-331.

1917 Z Zuñi Chronology. National Academy of Sciences, Proceedings 3:280-283.

1931 N. C. Nelson's Stratigraphic Technique in the Reconstruction of Prehistoric Sequences in Southwestern America. In Methods in Social Science, edited by S. A. Rice, pp. 275-283. University of Chicago Press, Chicago.

Stanley, S. M.
1979 Macroevolution: Pattern and Process. Freeman, San Francisco.

Stanley, S. M., W. O. Addicott, and K. Chinzei

1980 Lyellian Curves in Paleontology: Possibilities and Limitations. Geology 8:422-426.

Steward, J. H.

1929 Diffusion and Independent Invention: A Critique of Logic. American Anthropologist 31:491-495.

1942 The Direct Historical Approach to Archaeology. American Antiquity 7:337-343.

1944 Re: Archaeological Tools and Jobs. American Antiquity 10:99-100.

Stirling, M. W.

1929 Discussion of Mr. Hodge's Paper. In Report of the Conference on Midwestern Archaeology, pp. 24-28. National Research Council, Bulletin 74. Washington, DC.

1932 The Pre-Historic Southern Indians. In Conference on Southern Pre-History, pp. 20-31. National Research Council, Washington, DC.

Strong, W. D.

1935 An Introduction to Nebraska Archeology. Smithsonian Miscellaneous Collections 93(10). Washington, DC.

Taylor, R. E.

1985 The Beginnings of Radiocarbon Dating in American Antiquity: A Historical Perspective. American Antiquity 50:309-325.

1987 Radiocarbon Dating: An Archaeological Perspective. Academic Press, Orlando.

Thomas, C.

1894 Report on the Mound Explorations of the Bureau of Ethnology. Bureau of Ethnology, Annual Report 12:3-742.

Thomas, D. H.

1981 How to Classify the Projectile Points from Monitor Valley, Nevada. Journal of California and Great Basin Anthropology 3:7-43.

Thompson, R. H.

1956 An Archaeological Approach to the Study of Cultural Stability. Society for American Archaeology, Memoir $11: 31-57$.

Trueman, E. R.

1979 Species Concept. In The Encyclopedia of Paleontology, edited by R. W. Fairbridge and D. Jablonski, pp. 764-767. Dowden, Hutchinson and Ross, Stroudsburg, PA.

Tylor, E. B.

1881 Anthropology. Watts, London.

Van Riper, A. B.

1993 Men among the Mammoths: Victorian Science and the Discovery of Human Prehistory. University of Chicago Press, Chicago.

Vrba, E. S.

1980 Evolution, Species and Fossils: How Does Life Evolve? South African Journal of Science 76:61-84.

Wedel, W. R.

1938 The Direct-Historical Approach in Pawnee Archaeology. Smithsonian Miscellaneous Collections 97(7). Washington, DC.

Willey, G. R.

1936 A Survey of Methods and Problems in Archaeological Excavation, with Special Reference to the Southwest. Unpublished M.A. thesis, Department of Anthropology, University of Arizona, Tucson.

Willey, G. R., and P. Phillips

1958 Method and Theory in American Archaeology. University of Chicago Press, Chicago.

Willey, G. R., and J. A. Sabloff

1993 A History of American Archaeology, 3rd ed. Freeman, 
New York.

Wissler, C.

1916 The Application of Statistical Methods to the Data on the Trenton Argillite Culture. American Anthropologist 18:190-197.

1923 Man and Culture. Crowell, New York.

Youngquist, W.

1967 Fossil Systematics. In Essays in Paleontology and Stratigraphy, edited by C. Teichert and E. L. Yochelson, pp. 57-62. University of Kansas Press, Lawrence.

\section{Note}

1. It is appropriate to lump geology and paleontology here, as the latter served largely as the handmaiden of the former until Darwin's theory of organic evolution prompted the emergence of modern paleobiology (e.g., Nowlan 1986; Youngquist 1967).

Received April 8, 1999; Revised September 2, 1999; Accepted December 13, 1999. 